\title{
Physicochemical Properties of Macaranga (Gamu) used in Kalinga Basi (Bayas) Production
}

\section{Divina Alunday - Balocnit}

\author{
Kalinga State University, Philippines
}

Received: 12 Oct 2020; Received in revised form: 24 Dec 2020; Accepted: 29 Dec 2020; Available online: 31 Dec 2020

(C2020 The Author(s). Published by Infogain Publication. This is an open access article under the CC BY license

(https://creativecommons.org/licenses/by/4.0/).

\begin{abstract}
This study focused on assessing the physisco-chemical properties of Gamu used in Kalinga basi/ bayas production. Specifically, this study covers the ethnobotanical profile of the binuwa tree. The fruit of the binuwa tree is the gamu used as yeast to ferment in the production of bayas. Some of the chemical components of this fruit are also analyzed in this study. The physical and chemical characteristic of the bayas was also studied. This study's ultimate goal was to assess the physicochemical properties of gamu fruit used in basi/bayas production. Phytochemical analysis was used to get data on the chemical properties of the gamu and bayas. Survey methods and photo-documentation were applied to gather data on the physical characteristics of the local wines. The study found out that the binuwa tree is naturally grown in thick forests in the province and that its dried fruit, which is the gamu, is used as a starter to ferment basi/bayas. This fruit contains flavonoids and tannins responsible for antimicrobial activity and astringency of the wine, respectively. The basi/bayas have an alcohol content of $9.79 \% \mathrm{v} / \mathrm{v}$, Reducing Sugars 4.7\% w/w, pH of 3-4, and a total acid of 0.64g/lo0g of bayas. With these findings, it is recommended that interventions be done to assess the proper propagation of gamu to increase its supply.
\end{abstract}

Keywords-Physicochemical, Gamu, Bayas.

\section{INTRODUCTION}

People have been making and consuming wine from time immemorial. Fruits other than grapes are also used to make wine. Winemaking has developed by hit and trial ( https://doi.org/ ).

Sugarcane is one of the most popular materials used in producing local wine. It is one of the tallest members of the grass family, with the potential to grow up to $14 \mathrm{ft}$ high under tropical conditions.

Gamu is a wild plant. Basi/ bayas producers use the fruit as a starter for the fermentation process. It is called binunga or biluan in Tagalog, himindang in Bicol, and kuyonon in Bisaya. It is scientifically named Macaranga tanarius (L) (wikipidea.org./wiki/ )

Gamu is a fruit that is used as a starter for the fermentation of bayas. This fruit is unknown, and even the tree that bears this is also familiar to most people in Kalinga. Only those who are producing bayas see the fruit and the tree. This tree is essential for bayas production. This study's primary aim is to explore important information that would help understand the plant's ethnobotanical profile and the physical and chemical properties of the gamu fruit.

Basi/bayas are the local wine of Kalinga. Basi/ bayas are produced by fermenting boiled sugar cane juice. The juice is boiled in vats and stored in an ammoto ( earthen jar ). Once it has been cooled, dried gamu fruit is mixed with the liquid used to start the fermentation process. The mixture is left for at least three months to ferment and up to at least a year to be ready for drinking. The final product is a brown color and has a sweet and sour flavor. It is called bayas in Kalinga.

Bayas is an essential cultural product in Kalinga, but it is observed that few people are engaged in bayas production. There is a low supply of bayas in the locality, but the demand is high, especially during celebrations, rituals, and other cultural activities. 
The foremost factor they consider to affect the supply is the gamu fruit availability used as a starter for fermentation. Gamu is the fruit of the wild plant called binuwa, that is found in natural forest. This plant is growing naturally in the woods. The bayas producers patiently wait for the tree to bear fruit, then they will harvest it when it is matured. The availability and supply of the gamu fruit are beyond the basi producers' control because it depends on nature's provision. It is the significant factor that controls production, according to them.

With the above observations, the researcher intends to conduct a preliminary study on gamu fruit to have a baseline in formulating programs and projects that would help address the problems. There should be increased production of bayas to have increase family income.

An understanding of the physicochemical properties of gamu may define specific influences on process efficiency and wine quality. The analysis may also be used to assess if the basi/bayas will be well accepted by the regular wine consumers and can be an exciting product in the market.

This study aimed to present the physicochemical components of gamu fruit and some of the chemical properties of Kalinga Basi/ bayas. Investigation of some of the chemical elements and the wild plant's role ( $\mathrm{Gamu}$ ) in basi processing was also included in this study.

Specifically, it aimed to undertake the following: to document the ethnobotanical profile of the binuwa plant; to determine the chemical components of the Gamu fruit; to explore the function of each chemical component of the gamu fruit in bayas production; to present the procedure in the production of Kalinga basi /bayas; and to assess the Physicochemical Properties of the Kalinga basi/bayas as to ingredients and materials used, processing, storage and materials used, packaging, and chemical properties as to alcohol content, reducing sugar, and total acid.

\section{MATERIALS AND METHODS}

The materials that were investigated in this study were the basi/ bayas and gamu fruit. The bayas were taken from Lower Tanudan. It was taken from the producers who have been engaged in basi production for almost ten (10) years. The bayas used was a one-year-old wine. Another material was the dried gamu fruit. It was taken from the same basi/ bayas producer. The sample was brought to the Department of Science and Technology, Tuguegarao City Branch, for chemical analysis.

\section{Photo documentation}

The binuwa tree was documented from its natural habitat. Pictures were taken last May 2018.

\section{Chemical Analysis}

The gamu fruit and the basi/ bayas were collected and subjected to chemical analysis. The experimental research design $75 \%$ actual laboratory set up was utilized in the study. The testing process was following the laboratory procedure and quality control of the DOST, Tuguegarao City.

Another sample of Kalinga basi was brought to DOST, CAR.

\section{Phytochemical Screening (Stated in the Report Analysis )}

Procedure: The extract was evaporated to incipient dryness and tested for the presence of the stated phytochemicals following Guevara et al. ( 2005 ). A Guide book to Plant Screening: Phytochemicals and Biological.

\section{RESULTS AND DISCUSSION}

1. Ethnobotanical Profile of Binuwa Plant

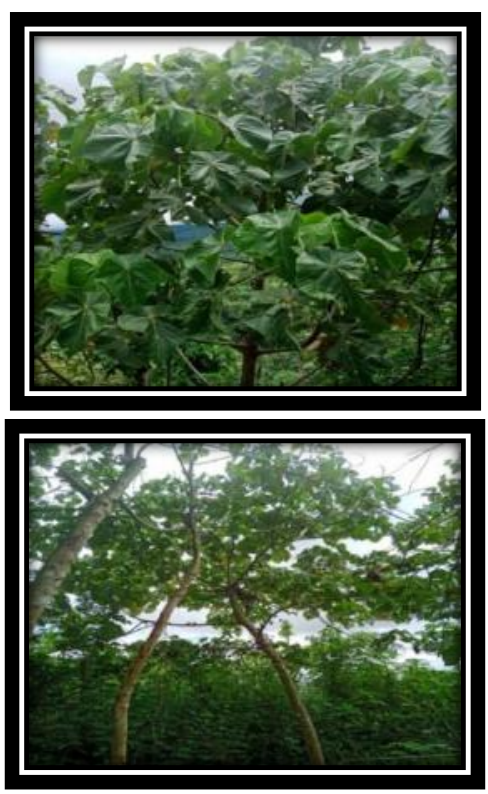

Fig. 1. BINUWA TREE 

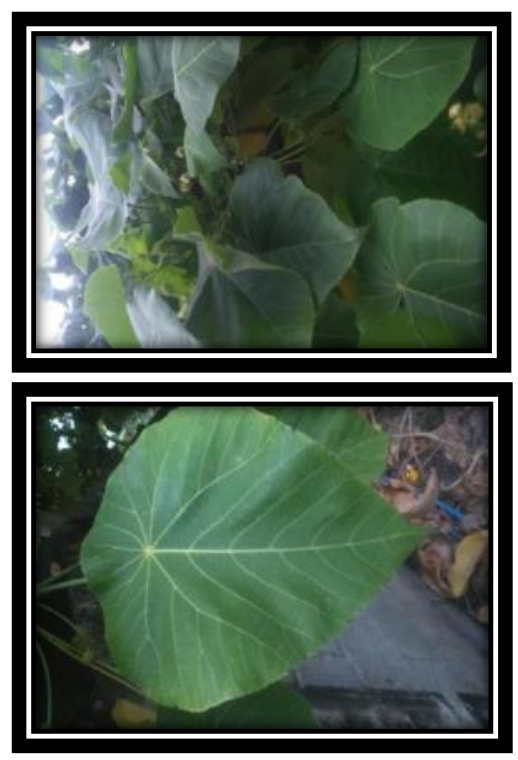

Fig. 2. BINUWA LEAVES
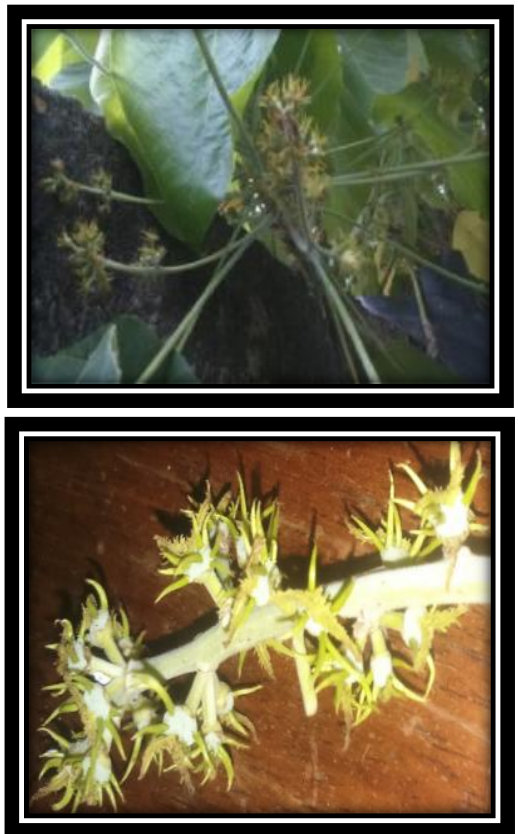

Taxonomy/ Nomenclature

Kingdom: Plantae

Family: Euphorbiaceae

Genus: Macaranga

Species: tanarius

Scientific Name: Macaranga tanarius

Common Names:

\author{
Binuwa - Kalinga \\ Binunga - Ilokano \\ Binonga - Tagalog ( Bis ) \\ Binungan - Tagalog
}

\title{
Botany
}

Binuñga/ binuwa is a small, dioecious tree, growing to a height of 4 to 8 meters (Fig. 1 ). The leaves are peltate, ovate to oblong-ovate, with entire or toothed margins, with a rounded base and pointed apex (Fig. 2). Male flowers are small and slender, branched peduncles. Female flowers are in simple panicled spikes. Capsules are 10 to 12 millimeters in diameter, of 2 or 3 cocci, covered with pale, waxy glands and soft, scattered, elongated spinelike processes (Fig. 3). The fresh fruits are green, with a spinelike process. (Stuart, G. Jr. M.D.) If the fruit is dried, it has a hard covering capsule colored black and a challenging spine-like process (Fig. 4 ). It is called gamu in the local dialect. 


\section{Distribution}

It is found in thickets and secondary forests, at low and medium altitudes in Kalinga's woods; specifically, it is naturally growing in the woods of Upper Kalinga.

\section{Folkloric Use}

In Kalinga, the dried fruit or gamu is used as a starter for local wine/bayas fermentation. It is the only use of gamu, according to the folks who served as the interviewee.

\section{Chemical components of the gamu fruit}

\begin{tabular}{|l|l|l|l|l|l|}
\hline Sample Code & $\begin{array}{l}\text { Sample } \\
\text { Description }\end{array}$ & Parameter & Result & Method Used & $\begin{array}{l}\text { Date } \\
\text { Analysis }\end{array}$ \\
\hline CHE-0718 & $\begin{array}{l}\text { Dried gamu } \\
\text { fruit }\end{array}$ & $\begin{array}{l}\text { Phytochemical } \\
\text { Screening }\end{array}$ & & $\begin{array}{l}\text { Guevara et al. } \\
(2005)\end{array}$ & July 16, 2018 \\
\hline & & Flavonoids & + & Test Tube Method & \\
\cline { 3 - 5 } & & Tannins & + & Spot Test for Tannins & \\
\cline { 3 - 5 } & & Saponnins & - & Froth Test & \\
\hline
\end{tabular}

\section{Test Report No. : 2018-465 Laboratory Reference No.: R2-072018-CHE-0491}

From the result of the Phytochemical screening of dried gamu fruit, it was found out that the extract contains flavonoids and tannins as reflected on the positive reaction to the test undergone. Further, the section negatively reacted to the Saponin test, thus preventing this chemical on the gamu fruit.

\section{Role of each chemical component of the gamu fruit}

\begin{tabular}{|l|l|}
\hline CHEMICAL & ROLE/FUNCTION \\
\hline Flavonoids & $\begin{array}{l}\text { antimicrobial characteristics having properties of antifungal, antiviral, and antibacterial } \\
\text { activity; preservative; antioxidant; as co-pigments with anthocyanins to increase the color of } \\
\text { red wines }\end{array}$ \\
\hline Tannins & $\begin{array}{l}\text { responsible for the aroma, flavors, astringency, and mouthfeel of the wine; color; aging } \\
\text { ability and texture of the wine ( bitterness ), natural preservative of the wine, }\end{array}$ \\
\hline
\end{tabular}

Acids, sugars, and tannins are the most prominent contributors to wine flavor. Tannins, or phenol compounds, give the wine an astringent mouth feel, and sugars determine the wine's sweetness. Yet to make things even more complicated, these chemicals' interaction seems to depend on growing conditions and fermentation practices (Coombs).

One of the reasons that tannins are essential in wine is that they affect the mouthfeel of the wine. The way we sense is by a mixture of taste and also touch. Tannins can have a bitter taste, especially when they are smaller. But the primary way we feel them is by touch: they are astringent. They bind to proteins in our saliva, and then the tannin-protein complexes precipitate, giving a drying sensation in the mouth (wineanorak.com).

The astringent nature of tannins can be moderated by the presence of sugar or other wine components. Interestingly, tannins are more astringent with lower $\mathrm{pH}$ (that is, wines with higher acidity taste more astringent, even with the same tannin content) and less astringent with increasing alcohol. However, the bitterness of tannins rises with alcohol level and is unchanged by $\mathrm{pH}$ changes (wineanorak.com).

Effects of tannins on the drinkability and aging potential of wine

Tannins are a natural preservative in wine. Un-aged wines with high tannin content can be less palatable than wines with a lower level of tannins. Tannins can be described as leaving a dry and puckered feeling with"furriness" in the mouth that can be compared to a stewed tea, which is also very tannic. This effect is particularly profound when drinking tannic wines without the benefit of food (wikipedia.org).

Many wine lovers see natural tannins as a sign of potential longevity and age ability. Tannins impart a mouth- 
puckering astringency when the wine is young but "resolve" into delicious and complex elements of "bottle bouquet" when the wine is cellared under appropriate temperature conditions, preferably in the range of a constant 55 to $60^{\circ} \mathrm{F}\left(13\right.$ to $\left.16^{\circ} \mathrm{C}\right)$. Such wines mellow and improve with age, with the tannic "backbone" helping the wine survive for as long as 40 years or more (wikipedia.org).

Li \&Xu have reported that quercetin extracted from lotus leaves may be a promising antibacterial agent for periodontitis, detoxifying agents, and antimicrobial defensive compounds. Flavonoids have roles against frost hardiness, drought resistance and may play a functional role in plant heat acclimatization and freezing tolerance (ncbi.nlm.nih.gov).

\section{The production process of bayas}

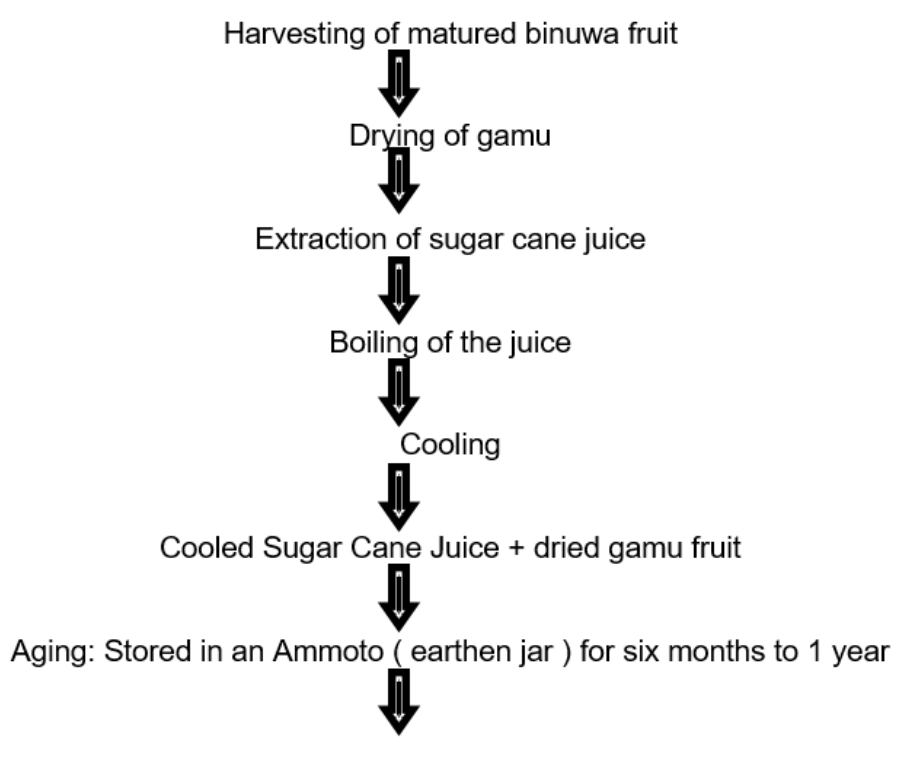

Packaging

\section{Fig.5: Process in making basi/bayas}

The procedures involved in producing basi include the sugar cane, dried gamu fruit, and the volume of basi being made. Recipes for the basi require the winemaker to monitor and regulate the amount of fermenter/yeast, the fermentation process, and other steps of the process. The basi production process still uses the traditional procedure, from sugar cane juice extraction; boiling; cooling; mixing of the fermentation starter, storing, then finally aging (Fig. 5 ).

The matured sugar cane stems are crushed using the dapil to extract the juice. The extracted juice is boiled. After which, it is brought to cooling. Once this is cooled, the dried gamu fruit is mixed. Two kilos of dried gamu is mixed with one full "ammoto" (earthen jar) of cooled juice. Then, the mixture is fixed for storage in the darkroom. It will take six (6) months to ferment and one year to age. The aged local wine is called bayas in Kalinga.

Other local wine procedures include packaging and quality control. But, in the basi/bayas production, there is no proper packaging and quality control since it is not supervised and monitored by the authorities concerned.

\section{Physicochemical Properties of Kalinga basi}

A. Ingredients and materials used for basi/bayas production Sugar cane juice + dried gamu fruit $=$ bayas

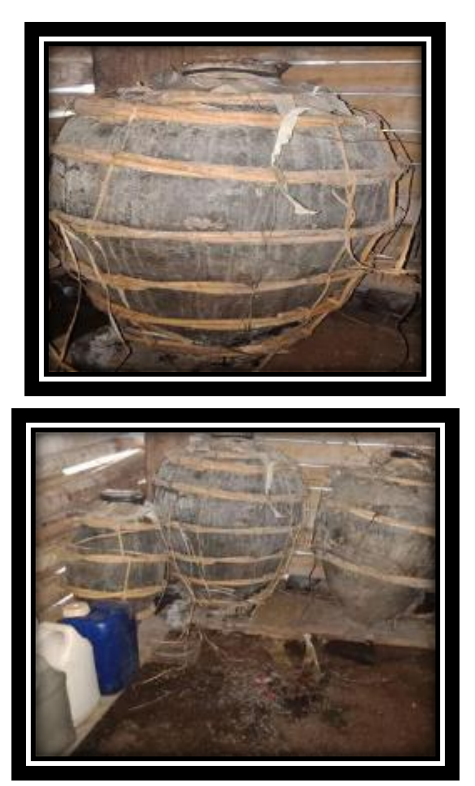

Fig. 6. Bayas stored in an Ammotto (earthen jar)

The basi is aged in an "ammoto" ( earthen jar ) for six months to 1 year. The minimum age of the basi is three months, but according to the elders who are basi drinkers, the taste is not good if it's only three months fermentation. The age of the basi affects the like because the fermentation process depends on the amount of sugar present in the juice extract. The sugar takes time to be fermented to alcohol. If the basi is young, the taste is too sweet.

It shows how the basi is being stored in the "ammoto." The wine is placed in the "ammoto," and it is covered with banana leaves or clean cloth. It is stored there for almost a year. But it can be prolonged to age. The more years it is stored, the better the taste. The older the bayas, the better the like, according to the owner of these bayas, Mr. Alinduwat. 


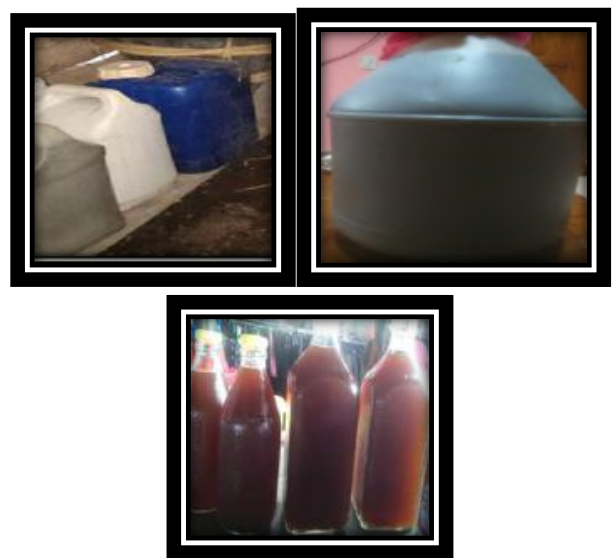

Fig. 7. Packaging of the basi/ bayas sold in the market

If the basi is aged already, it is now ready to be transferred in a gallon. The wine is stored in the galloon if it is prepared for drinking and selling if there are buyers. Then, the second seller will place it in a bottle for sale.

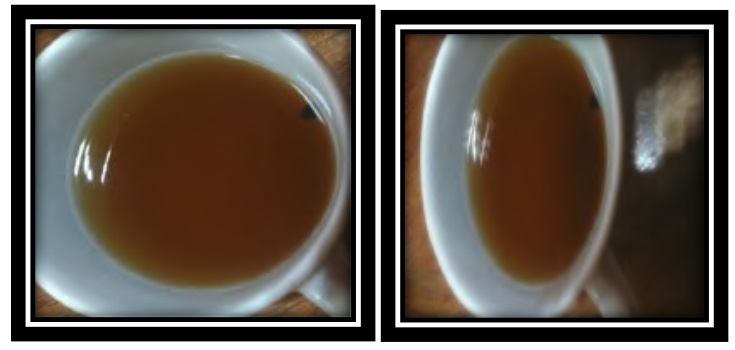

Fig. 8. Kalinga basi / bayas

The Kalinga basi that is ready for drinking is colored light brown to dark brown.

B. Chemical Properties of basi/bayas

\begin{tabular}{|l|l|}
\hline PROPERTIES & BASI/BAYAS \\
\hline Alcohol content, \%v/v & $9.79^{*}$ \\
\hline Reducing sugar, \%w/w & $4.7 *$ \\
\hline $\mathrm{pH}$ & $3-4$ \\
\hline$\%$ Total acid & $0.64 \mathrm{~g} / 100 \mathrm{~g}$ \\
\hline $\begin{array}{l}\text { Test Report No. : 2018-482 } \\
\text { No.: R2-072018-CHE-0508 }\end{array}$ & *Req. Ref. No. CAR - \\
062019-CHE-0557 &
\end{tabular}

The bayas sample was brought to the DOST, Tuguegarao City Branch, for chemical analysis. The $\mathrm{pH}$ and $\%$ total acid was analyzed by expert personnel from the authorized unit of the DOST following the specific procedure as stated on the Result Analysis given: a. Aliquot portion of sample is diluted with recently boiled and cooled water until it appears slightly colored.

b. The solution from (a) is titrated with $0.5 \mathrm{M}$ standard sodium hydroxide solution using phenolphthalein indicator.

Another sample was brought to DOST, CAR, Regional Standard and Testing Laboratory for Alcohol content and Reducing Sugar content analysis ( Refer to the table).

\section{CONCLUSIONS}

From the above findings, it is concluded that:

- Binuwa tree is naturally grown in Kalinga's thick forests, particularly in the upper part of the province.

- There are many folkloric uses of binuwa, but in Kalinga, they only use the dried gamu fruit as a yeast agent in producing basi/bayas.

- The dried gamu fruit contains flavonoids and tannins. These chemicals serve as natural preservatives of the basi/bayas. Flavonoids have antimicrobial characteristics having properties of antifungal, antiviral, and antibacterial activity. Tannins are also responsible for the aroma, flavors, astringency, and mouthfeel of the wine.

- As to the chemical properties, bayas has an alcohol content of $9.79 \% \mathrm{v} / \mathrm{v}$, Reducing Sugars $4.7 \% \mathrm{w} / \mathrm{w}$, $\mathrm{pH}$ of $3-4$, and with titratable acidity of $0.64 \mathrm{~g} / 100 \mathrm{ml}$

\section{RECOMMENDATIONS}

Interventions should be done to assess the proper propagation of gamu to increase its supply.

The new challenge is to enhance the appeal and value of bayas by traditional technology, which should be achieved to strengthen the regional identity of bayas. Outstanding features should be performed, such as quality and flavor compared to other good quality wines.

An understanding of the physicochemical properties of bayas may define specific influences on process efficiency and wine quality. The analysis may also be used to assess if the basi/bayas will be well accepted by the regular wine consumers and can be an exciting product in the market. 


\section{REFERENCES}

[1] Bermosa, Nobert Soloria; 2008; Production of Popular Native Wines in the Philippines

[2] Carreon - Alvarez, A. et. Al. Assessment of Physicochemical Properties of Tequila Brands: Authentication and Quality; Departamento de Ciencias Exactas y Naturales, Centro Universitario de los Valles (CUVALLES), Universidad de Guadalajara, Carretera Guadalajara-Ameca Km. 45.5, 46600 Ameca, JAL, Mexico

[3] Coombs, Amy; 2009; ScientiaVitis: Decanting the Chemistry of Wine Flavor (https://www.sciencehistory.org/distillations/magazine/)

[4] Davidovic, SM, et al.; Physicochemical, Antioxidant and Sensory Properties of Peach Wine Made from RedHaven Cultivar.

[5] Kettem, Vanessa L.; 2013 Documentation on Sugarcane Wine (fvayash) Processing in Sadanga, Mountain Province

[6] Marcia N. C.et. Al.; Physical-Chemical Evaluation of Wines Subjected to Gamma Irradiation for Aging; Center of Nuclear Energy in Agriculture (CENA/USP - SP), Department of Radiobiology and Environment, Av. Centenário

[7] Park, K. I., et al.; Symposium on Indigenous Fermented Foods, Bangkok, Thailand

[8] Peralta, Mark Robert Bryan, et.al.:Lambanog Wine Manufacturing; Sanghaya Inc.

[9] Rivera-Espinoza, Y. et. Al. Characterization of a Wine-like Beverage Obtained from Sugarcane Juice; Departamento de Graduados e Investigación en Alimentos, Escuela Nacional de Cienci

[10] Singaravadivel, K. et. Al. physicochemical properties of fresh and stored coconut palm toddyPhysicochemical Properties of Fresh and Stored Coconut Palm Toddy Department of Food Microbiology, Indian Institute of Crop Processing Technology, Thanjavur, Tamil Nadu, India

[11] Stuart, Godofredo U. Jr. MD. ; 2016; Binunga

[12] Trinidad, Richard; 2013; Studies on Production of Native Wine from Rice Vijay Wadhai and Manjusha Gondane 